\title{
Joana, de Bernardo Kucinski, e a representação dos desaparecidos durante a ditadura
}

\author{
Joana, by Bernardo Kucinski, and a representation of the disappeared during \\ the dictatorship \\ Diego Kauê BAUTZ* \\ Universidade Estadual Paulista "Júlio de Mesquita Filho" (UNESP)
}

\begin{abstract}
RESUMO: Espera-se, aqui, iluminar alguns traços da escrita de Bernardo Kucinski referentes ao período da ditadura militar brasileira. Como o escritor tem uma considerável produção que abarca esse período, analisou-se detidamente apenas um conto do autor para, assim, perceber com o máximo de atenção a constituição do universo narrativo. O conto analisado foi "Joana", publicado em Você Vai Voltar pra Mim e Outros Contos (2014), pois, como já existem estudos sobre esse texto, foi possível estabelecer um diálogo com leituras anteriores a fim de ampliar a visão sobre o conto e, a partir disso, identificar alguns artifícios recorrentes dos quais o escritor se vale para representar o período da ditadura. Desta forma, foi possível identificar que Kucinski, além de denunciar em sua obra os crimes cometidos pela ditadura, insere-se em uma certa tradição da literatura brasileira voltada para a representação de projetos de nação orientados por um gerenciamento da morte.
\end{abstract}

PALAVRAS-CHAVE: Bernardo Kucinski. Conto. Joana. Ditadura. Desaparecidos.

\begin{abstract}
Here, we hope to illuminate some traces of Bernardo Kucinski's writing regarding the period of the Brazilian military dictatorship. As the writer has a preference for production that encompasses this period, only one short story by the author was carefully analyzed so that we could perceive with the utmost attention the constitution of the narrative universe. The short story
\end{abstract}

\footnotetext{
"Mestre em Literatura e Vida Social pela Universidade Estadual Paulista "Júlio de Mesquita Filho" (UNESP) e, atualmente, bolsista de doutorado do CNPq pela mesma Universidade. Assis, São Paulo: diegobautz@hotmail.com
} 
analyzed was “Joana”, published in Você Vai Voltar pra Mim and Outros Contos (2014), because, as there are already studies on this text, it was possible to establish a dialogue with previous readings to broaden the vision of the short story and, from this, identify some recurrent artifices that the writer uses to represent the period of the dictatorship. In this way, it was possible to identify that Kucinski, in addition to denouncing crimes committed by the dictatorship in his work, is part of a certain tradition in Brazilian literature focused on a representation of nation projects guided by death management.

KEYWORDS: Bernardo Kucinski. Tale. Joana. Dictatorship. Disappeared.

\section{INTRODUÇÃO}

Bernardo Kucinski é um jornalista de extensa carreira, além de cientista político e escritor. Tendo dedicado a maior parte da sua vida profissional ao jornalismo, em 2011, com 74 anos, publicou K. O Relato de Uma Busca, seu romance de estreia na literatura. Nesse romance já há um dos aspectos que caracterizam a obra do escritor e que será analisado aqui neste trabalho: a representação do período ditatorial brasileiro e dos desaparecidos durante o regime. Além de K., Kucinski publicou Você Vai Voltar pra Mim e Outros Contos (2014), coletânea de contos em que publicou "Joana", texto que será aqui analisado; Alice Não Mais que de Repente (2014), romance policial que aborda o assassinato de uma professora da USP; Os Visitantes (2016), novela em que o escritor coloca o narrador-personagem de $K$., seu primeiro livro, em diálogos com personagens de leitores que questionam o nível de veracidade do seu primeiro romance; Pretérito Imperfeito (2017), romance sobre uma relação de pai e filho extremamente problemática; A Nova Ordem (2019), romance que apresenta uma sociedade fascista conduzida por líderes autoritários e patéticos, além de Júlia: nos campos conflagrados do Senhor (2020), mais um romance ambientado no período ditatorial, desta vez centrado em Júlia, uma mulher adulta que descobre ter sido retirada de sua mãe biológica quando criança em um esquema envolvendo o regime militar, a Igreja e diversos funcionários do Estado, como delegados, escrivães e despachantes. 
Percebe-se que, apesar de recente, é constante o ritmo da produção literária de Bernardo Kucinski, assim como é recorrente em sua obra o tema da ditadura militar brasileira. O conto "Joana”, publicado em Você Vai Voltar pra Mim e Outros Contos, é mais um texto do escritor que, além de ser ambientado no contexto da ditadura, gira em torno do problema dos desaparecidos nesse período, assim como seu conto "O Velório", publicado no mesmo livro, e seu romance K.: Relato de uma Busca. Em razão dessa recorrência temática na obra de Kucinski e, compreendendo-a como um sinal da preocupação do autor em denunciar esse tipo de crime cometido no regime militar, o presente estudo parte do questionamento sobre quais os principais aspectos referentes a esse tema evidenciados na produção do escritor. Como tal tarefa demandaria mais que um artigo, analisou-se detidamente o conto "Joana", em diálogo com outros estudos sobre a produção de Kucinski, para identificar com o máximo de nitidez neste texto o modo como Kucinski representa o período ditatorial brasileiro, principalmente no que se refere à maneira como o autor denuncia a violência, o autoritarismo e os crimes cometidos sob tal regime, sobretudo os crimes envolvendo o desaparecimento de vítimas.

Basicamente, o enredo do conto "Joana", apresentado por um advogado que narra a história da protagonista que dá nome ao conto, focaliza uma ex-cliente do narrador buscando reencontrar seu marido Raimundo, sequestrado pela polícia na época da ditadura. O narrador ressalta a persistência de Joana que não desiste de reencontrar seu marido, mesmo após muito tempo e de, inclusive, já ter sido informada por um cardeal sobre a morte do seu companheiro; além de ter recebido do Estado um pseudoatestado confirmando o óbito. Portanto, a história de Joana se desenvolve entre o silêncio por parte do Estado sobre o que ocorrera com Raimundo e a sua infindável esperança de reencontrar o marido, pois não acredita que ele realmente tenha morrido, já que o Estado não fornecera acesso ao corpo nem a informações detalhadas sobre as circunstâncias do óbito.

Ao analisar o romance K.: Relato de uma Busca, Andersson (2014) também ressalta a busca do protagonista por uma pessoa desaparecida no período da ditadura, no caso, a sua filha. A pesquisadora salienta, ainda, o complexo contrato de leitura da obra, já que, nesse romance, Kucinski mescla elaborações ficcionais com memórias sobre sua irmã presa pelos militares e desaparecida durante a ditadura. Para Andersson, o modo como essa busca do protagonista por sua filha é narrada em $K$ sugere, em primeiro lugar, uma luta contra a negação dos fatos que pudesse deixar a filha cair em esquecimento - o 
que justifica a escolha por uma voz narrativa que organiza o relato confundindo os limites entre apresentações de fatos e elaborações ficcionais, pois assim a narrativa se apresenta como mais uma versão sobre o ocorrido, porém distinta e discordante da versão oficial. Além disso, o romance de Kucinski expressa a "ausência" como elemento central da obra, já que não apenas a cena do desaparecimento da filha não faz parte do livro como o próprio contexto ditatorial que emoldura a trama representa a ausência de direitos. Ademais, de acordo com a pesquisadora, a busca de $K$., o protagonista, é marcada ao longo do romance pela ausência de vestígios, pois, embora o personagem tente por inúmeras vezes e por diferentes caminhos encontrar sua filha, tudo o que encontra é o vazio da absoluta falta de pistas sobre o que ocorrera.

Essa característica cíclica da narrativa, de acordo com Andersson (2014), é típica de relatos sobre traumas, nos quais as repetições aparecem como tentativas de se representar o irrepresentável de eventos traumáticos. Tal característica, para a pesquisadora, assemelha-se às buscas de Joana, protagonista do conto aqui analisado, pois ela também insiste em buscar repetidamente o marido assassinado pela ditatura, mas, obviamente, sempre retorna, sem sucesso, ao ponto de partida. Assim como o próprio Bernardo Kucinski repetidamente toma o período ditatorial como material narrativo.

Araújo e Fernandes (2016) notam essa recorrência temática na obra de Kucinski ao analisarem as formas de representação da violência e de traumas na constituição dos personagens dos contos "Sobre a Natureza do Homem", "Joana" e "Você Vai Voltar pra mim", todos ambientados no contexto da ditadura e publicados na coletânea Você Vai Voltar pra mim e Outros Contos, de Bernardo Kucinski. O conto "Sobre a natureza do homem", sempre de acordo com os pesquisadores mencionados, apresenta, pela perspectiva do narrador-personagem Rui, militante e colega de faculdade da protagonista, uma história de tortura exercida por representantes do Estado ditatorial e do consequente trauma da vítima da tortura, a protagonista Imaculata, universitária simpatizante de movimentos militantes. Há, nesse conto, o foco nas consequências da tortura, enfatizando o horror da violência por meio do contraste entre as reflexões de Imaculata sobre a natureza do ser humano e o sadismo dos torturadores quando a violentaram. O conto "Joana", por sua vez, representa os limites da tortura psicológica sofrida por Joana que, embora não tenha sofrido nenhuma violência física, vive presa ao evento traumático de ter o marido raptado, torturado e assassinado por policiais que, ao sumirem com o corpo 
da vítima, impedem Joana de ver o corpo morto do marido para vivenciar o luto. Já o conto "Você vai voltar pra mim", ainda segundo Araújo e Fernandes, apresenta, pelo ponto de vista de um narrador em terceira pessoa, a história de uma mulher que, além de ser torturada a caminho de uma audiência com um juiz, não encontra apoio algum quando, durante a audiência, resolve denunciar os abusos que sofrera. Como se percebe, nos três contos mencionados há, como pano de fundo que estrutura as torturas, a representação de traumas decorrentes de diversas formas de violência praticadas durante um período marcado pela ausência de garantias constitucionais.

Essa lógica, entretanto, não é inédita na história da literatura brasileira, tampouco na história do país. Diniz (2017), ao refletir sobre como ficcionalizações de diferentes modos de vida incorporam repertórios conceituais da filosofia política, da crítica cultural e de outros campos da produção científica, identifica, ao longo da história da literatura brasileira, a repetição de um modelo de pensamento orientado pela hierarquização de formas de vida. Há, de acordo com o pesquisador, procedimentos de normatização da vida, da sociedade e do sistema literário orientados por definições de condições humanas e animais de vida, isto é, de formas cívicas e, portanto, dignas de vida em oposição a formas de vida (ou, de sobrevivência) precarizadas e, portanto, descartáveis, matáveis. Diniz ilustra seu ponto de vista mencionando obras literárias representativas de períodos distintos da literatura brasileira, mas todas organizadas em torno desse imaginário segundo o qual determinadas vidas seriam dispensáveis.

Esse imaginário, de acordo com Diniz, já pode ser notado no período indianista, mais explicitamente na épica de I-Juca-Pirama (1851), de Gonçalves Dias, cujo étimo de Pirama já prenuncia: "'[...] aquilo que há de morrer', 'o que é digno de morte' ou 'condenado heroicamente à morte'" (DINIZ, 2017, p. 149). Concepção esta que, sempre conforme Diniz, toca em Iracema (1865), de José de Alencar, cujo procedimento poético de mesclar tradições indígenas com o idioma português se orientou por uma noção que limitava o léxico indígena à ideia de uma língua morta, já que pertencente a uma "raça extinta". Posteriormente, essa característica do processo civilizatório brasileiro marcado por cálculos estatais que gerenciam a morte na organização da sociedade volta a ser representada. Em O Alienista (1982), por exemplo, de Machado de Assis, é possível identificar a ironização dos discursos da psiquiatria e do cientificismo positivista característicos da época, já que é o ideal cientificista do personagem Simão de Bacamarte 
que fundamenta a sua desrazão e o orienta em seu projeto de internar todos aqueles que considera loucos, ou, incapazes de fazer parte de uma sociedade em processo de modernização.

De maneira semelhante, a multidão de sertanejos perseguidos em Os Sertões (1902), de Euclides da Cunha, expressa a racionalidade liberal do Estado que, ao não assimilar o sertanejo como parcela produtiva de uma sociedade em vias de modernização, define-o como figura essencialmente antimoderna e, portanto, conveniente de ser enclausurada ou eliminada da sociedade. Em contraste a essas obras, Diniz (2017) menciona Vidas Secas (1938), de Graciliano Ramos, Morte e Vida Severina (1955), de João Cabral de Melo Neto, Quarto de Despejo (1960), de Carolina Maria de Jesus, e A Hora da Estrela (1977), de Clarice Lispector, como exemplos de obras que, cada uma em diálogo com um contexto específico - dos sertões aos centros urbanizados -, representaram a continuidade dessa lógica de controle que determina como descartáveis alguns tipos de vida considerados desviantes do previsto pela racionalidade de Estado, mas todas orientadas por pontos de vista mais críticos a esse modelo de pensamento.

É nesse sentido crítico que a obra de Kucinski se enquadra, pois, além de o escritor representar um dos momentos da história brasileira quando essa lógica esteve mais evidente, fundamenta-se em uma proposta de se contrapor a determinadas versões sobre a ditadura cívico-militar brasileira que contestam o caráter autoritário e violento desse período. Para Santos e Fonseca (2018), como a tematização do período ditatorial brasileiro fora reprimida pelo Estado ao longo dos anos, a obra de Kucinski é revestida da importância de responder à necessidade de uma elaboração mais satisfatória da memória nacional sobre os eventos ocorridos nesse tempo.

Um dos tipos de acontecimentos infelizmente comuns nesse período e que Kucinski também recorrentemente aborda em suas obras é o desaparecimento de vítimas da ditadura - tema central do romance K.: Relato de uma Busca e dos contos "O Velório" e "Joana". Para as pesquisadoras, o romance $K$. representa a ausência, conforme já mencionado, mas, além disso, "[...] ilustra a angústia causada pela falta do corpo para fins de sepultamento e rituais de luto, já que essa ausência punha à prova a certeza da morte." (SANTOS; FONSECA, 2018, p. 146). No mesmo sentido, sempre conforme as pesquisadoras, o conto "O Velório", ao representar a cena de um velório que acontece 
sem a presença do cadáver a ser velado em função do desaparecimento do corpo, salienta o sofrimento de uma família impedida de vivenciar a experiência do luto por causa da forma extremamente violenta como o Estado exterminava seus opositores durante a ditadura. Conforme sabemos, o conto "Joana", de maneira semelhante, apresenta as consequências desse modo de ação do Estado na vida de Joana, protagonista que vive em busca do seu marido raptado, assassinado e eliminado por agentes da ditadura. Desta forma, "Tanto no romance quanto nos contos, se apresenta ao leitor uma atmosfera de intensa crueldade e desrespeito à dignidade humana, em um cenário marcado pelo abuso de poder e pela impunidade." (Idem, 2018, p. 148)

Compreende-se, portanto, que, assim como o romance K.: Relato de uma Busca, os contos de Bernardo Kucinski também tensionam os limites entre documento e ficção, principalmente quando ambientados no contexto do período ditatorial brasileiro. Os contos de Você Vai Voltar pra mim e Outros Contos, por exemplo "[...] foram inspirados em sessões da Comissão Nacional da Verdade a que o escritor Bernardo Kucinski assistiu em São Paulo no fim do ano de 2013." (VASCONCELOS, 2018, p. 12). Vasconcelos nos lembra que a Comissão funcionou como um instrumento para registrar as memórias daqueles que sofreram violações de direitos humanos desde 1946 até a promulgação da Constituição de 1988. A realização da Comissão, portanto, justificou-se pela possibilidade de trazer à tona fatos propositalmente silenciados por agentes governamentais envolvidos em atos de violação de direitos humanos durante o período ditatorial.

De acordo com Vasconcelos, eventos associados a esses abusos são ficcionalizados no conto "Joana". Um deles é o desaparecimento do corpo do personagem Raimundo, o que indica o interesse do Estado em manter determinados crimes sem resolução. Sobre o desaparecimento de Raimundo é possível, ainda, associa-lo ao fato histórico de agentes da ditadura perseguirem membros do grupo de militantes ligados à Igreja Católica denominado Ação Popular, pois, no conto, o personagem Raimundo, marido da protagonista e membro do grupo Ação Popular, é sequestrado em 1969, exatamente um ano após a promulgação do AI-5, quando, intensificada a repressão militar, o grupo Ação Popular é totalmente desarticulado e extinto em 1970. 
Além disso, como o relato do narrador de "Joana" é situado no ano de 1995, período quando o Estado buscava reconhecer alguns crimes cometidos durante a ditadura e ressarcir as vítimas, é possível identificar a formalização desse contexto no próprio tom jurídico pelo qual o narrador conduz a história, mencionando, inclusive, o desfecho do processo envolvendo a protagonista e a herança recebida por ela. Assim, é possível compreender que o conto "Joana" é apenas um exemplo do modo como Kucinski formalizou o período ditatorial em sua obra que, para Vasconcelos, tem como essência o elemento da "clandestinidade" motivada pela conjuntura da ditadura civil-militar brasileira, pois se orienta pela questão das pessoas que, nesse contexto e em consequência dele, "[...] se tornaram invisíveis para a sociedade, para as suas famílias, para eles mesmos e, depois de presos, foram 'apagados', da nossa sociedade através da morte ou, pior, do desaparecimento." (VASCONCELOS, 2018, p. 96). Porém, quais os artifícios utilizados por Kucinski para representar esse contexto em sua obra?

\section{Joana: "cadê o corpo?"}

A protagonista Joana, no início do conto, é apresentada já traumatizada, peregrinando em busca do marido assassinado. $\mathrm{O}$ narrador apresenta a personagem de maneira distanciada, salientando o lenço preto na cabeça da viúva que, entretanto, é caracterizada apenas como uma pessoa de aparência "comum":

\footnotetext{
Observem aquela mulher de lenço preto na cabeça, caminhando na calçada. Concordam comigo que parece uma pessoa comum? Que só chama a atenção por vagar sozinha tarde da noite, sendo idosa? Pois saibam que há uma história por trás das peregrinações dessa mulher. (KUCINSKI, 2014, p. 43)
}

Apesar dessa distância do foco narrativo que acompanha de longe a peregrinação de Joana, o narrador sugere que a personagem mora perto dali onde a história vai sendo contada: "Ela se chama Joana e mora aqui perto. Passa por esta rua a caminho do centro da cidade, onde dormem muitos moradores de rua. É a eles que ela busca." (Ibidem, p. 
43). Em seguida, porém, o nível de proximidade do narrador com Joana é mais bem delimitado:

\begin{abstract}
Vocês nunca conhecerão a história dessa mulher, se eu não a contar, pois só sabem dela os indigentes, com quem vocês certamente não conversam e, no outro extremo social, alguns príncipes da Igreja e advogados ilustres, os quais vocês também não frequentam. Eu conheço a história dela porque fui um dos seus advogados, embora não tão ilustre. (KUCINSKI, 2014, p. 43)
\end{abstract}

Percebe-se, aqui, uma demarcação do narrador também em relação aos leitores do conto, colocados por ele entre uma classe média da sociedade que "certamente" não conversa com "indigentes" e que tampouco tem contato com altos representantes da Igreja e da Lei.

O narrador, então, finaliza a descrição de Joana e apresenta breve e objetivamente Raimundo, o marido a quem a viúva busca:

O marido era metalúrgico e se chamava Raimundo. Católico praticante como ela. Vieram do Nordeste em busca de uma vida um pouco melhor em São Paulo. Já tinham dois filhos. Aqui Raimundo se ligou a um grupo da Ação Popular que organizava operários nas fábricas. (KUCINSKI, 2014, p. 44)

Na sequência, também de maneira sumária, mas em tom acusatório e com uma linguagem caracteristicamente pertencente ao campo do Direito, o narrador expõe o destino de Raimundo:

Um dia, bem cedo, a polícia foi à casa deles e levou Raimundo. Sem mandado de prisão, sem nada. Soube-se depois que ele foi espancado de modo tão brutal que morreu no mesmo dia. Seus gritos eram ouvidos em outras celas. Para ocultar o homicídio, no caso doloso e qualificado, pois acompanhado do crime acessório de abuso de autoridade, a polícia cometeu outro crime, o de 
ocultamento de cadáver. Sumiram com o corpo de Raimundo. (KUCINSKI, 2014, p. 44)

Logo em seguida, o narrador garante a comprovação de que os crimes foram cometidos, mas ressalta o fato de não haver pistas sobre o que fizeram com o corpo de Raimundo:

Tudo isso foi comprovado, depois que acabou a ditadura, por documentos e comissões em várias comissões. Só não se sabe, nunca se soube, para onde levaram o corpo e como se desfizeram dele. Se foi enterrado como indigente ou incinerado, ou disposto de outra forma. Isso nenhuma das diligências conseguiu elucidar. Foi um dos casos mais impenetráveis de desaparecimento, um caso em que nenhuma pista surgiu. (KUCINSKI, 2014, p. 44)

Então, no parágrafo seguinte, como uma maneira de articular as peregrinações de Joana às omissões do Estado, o narrador revela a crença da protagonista que a faz persistir na busca pelo seu marido, já que nunca teve acesso ao corpo dele ou informações mais detalhadas sobre o óbito. Além disso, nesse momento o narrador delega a voz para que a própria personagem questione sobre o destino do corpo de Raimundo:

Embora o próprio cardeal tenha assegurado a Joana que o marido foi espancado até não restar nele sopro de vida, ela não aceitou que ele tivesse morrido. Cadê o corpo? - ela perguntou. E sempre pergunta. Diz que só vai se considerar viúva no dia em que trouxerem o atestado de óbito de Raimundo e mostrarem sua sepultura. / Ela acredita que os espancamentos deixaram Raimundo desmemoriado, talvez até cego ou aleijado, e que desde então ele perambula pelas ruas, perdido, sem saber como voltar para casa. (KUCINSKI, 2014, p. 45)

Expostas as razões para as peregrinações de Joana, o narrador detalha a rotina da personagem, enfatizando o caráter repetitivo dessa busca: 
Uma ou duas noites por semana, ela junta algumas moedas e sai envolta em seu xale. Exibe a fotografia de Raimundo aos moradores de rua, pergunta se apareceu algum andarilho ou indigente desconhecido de mais idade e de tez branca. Se dizem que sim, ela quer saber debaixo de qual marquise ou em qual abrigo da Prefeitura ele está e vai atrás dele. No caminho vai deixando uma moeda aqui, outra ali. (KUCINSKI, 2014, p. 45)

Esse comportamento sistemático de Joana é revestido, em seguida, de um aspecto maquinal, sugerindo não apenas a perda de vitalidade da viúva em decorrência do assassinato do seu marido, mas, acima de tudo, a conjuntura desumana que exerce uma "força superior" sobre a protagonista que continua saindo "automaticamente" para procurar seu marido: "É como se uma força superior a fizesse se levantar automaticamente e sair errante pelas ruas à procura do marido. Quase como uma sonâmbula." (Ibidem, loc. cit.)

No entanto, ao final do conto, o narrador, de maneira sutil, contrasta a beleza da jovem Joana que não conhecera à Joana do tempo do narrado, a qual, apesar da ditadura e do tempo decorrido, sustenta o seu amor por Raimundo:

Joana era jovem quando assassinaram Raimundo. Eu não a conheci nessa época. Dizem que era muito bonita e nunca quis outro homem. Sim, pensando bem, acho que essa é sobretudo uma história de amor, um desses amores intensos que nem o tempo nem a ditadura conseguiram extinguir. (KUCINSKI, 2014, p. 45)

Tudo isso é narrado a partir de um ponto de vista distanciado, compartilhado pelo narrador com seus leitores, em relação à Joana e aos "indigentes" a quem ela busca na intenção de encontrar seu marido. Tal distanciamento é evidente no modo como o narrador se refere às passagens de Joana por "esta rua a caminho do centro da cidade", no "nosso quarteirão", de onde a protagonista sempre parte caminhando em direção ao centro. O narrador revela, assim, a intenção de dividir o seu ponto de vista com seus 
leitores que, assim como ele, também observam a cidade a partir de um ponto de vista intermediário, entre os "indigentes" e os "príncipes da Igreja e advogados ilustres". Sabese, porém, que, embora o narrador não se considere um dos "advogados ilustres", ele também exerce essa profissão e, na maior parte do conto, apresenta os acontecimentos sob uma perspectiva jurídica, num tom distanciado e burocrático; como pode ser percebido na maneira como apresenta o ambiente ocupado por personagens em situação de rua, além da história de Joana e da primeira avaliação sobre a persistência da viúva, segundo a qual Joana sairia pelas ruas "Quase como uma sonâmbula. Ou como se estivesse pagando uma promessa" (Ibidem, p. 45); o que o narrador não sabe definir, afinal, em suas palavras: "Não sei definir, sou advogado, e não psicólogo, só sei dizer que é uma necessidade psíquica dela que todos respeitamos. Inclusive os filhos." (Ibidem, loc. cit.)

Esse distanciamento do narrador persiste em seu ponto de vista sobre Raimundo, cuja trajetória de vida é narrada em um tom burocrático, afetado apenas ao mencionar a brutalidade policial ao espancar o trabalhador até a morte. De maneira breve e em um tom acusatório, o narrador nos conta sobre a chegada de Raimundo à São Paulo, a sua união junto a um grupo da Ação Popular e a subsequente chegada da polícia, "sem mandado de prisão, sem nada", à casa do trabalhador para leva-lo dali. Desta forma, porém, o narrador salienta o caráter autoritário da polícia, uma vez que o único comentário narrativo se refere à ausência de algum mandado que justificasse a busca por Raimundo.

Configura-se, assim, a coerência do ponto de vista narrativo de um advogado que se mantém, inicialmente, sem grande envolvimento com a protagonista, já que apresenta a história do casal de trabalhadores por uma perspectiva predominantemente jurídica. Essa perspectiva, no entanto, é tensionada durante o conto em momentos nos quais o narrador se aproxima mais de Joana, como quando mostra a descrença da personagem em relação às palavras do cardeal garantindo que Raimundo fora espancado até a morte. Embora "católica praticante", Joana duvida do líder religioso, assim como não acredita no "pseudoatestado" de óbito concedido pelo Estado. Nesse ponto, o narrador demonstra empatia com a personagem ao concordar que "De fato é um pseudoatestado, só serve para a família cuidar do inventário e seguir a vida. E Joana segue a vida, mas a seu modo.” (KUCINSKI, 2014, p. 45). Ao final do conto, a empatia do narrador com a protagonista é revelada de maneira ainda mais enfática, pois abandona a perspectiva jurídica para 
definir a trajetória de Joana como uma história de amor; assim sobrepondo a humanidade da protagonista à desumanidade da ditadura.

Além disso, a personagem Joana, embora inicialmente apresentada como uma mulher de aspecto comum, desde o início já tem sugerida sua ligação com a morte, uma vez que o narrador ressalta o seu "lenço preto na cabeça". Como se sabe, é justamente a morte de Raimundo que aciona as peregrinações de Joana, as quais conferem a excepcionalidade da história da personagem. Tal excepcionalidade pode ser condensada na crença de Joana de que Raimundo ainda estivesse vivo. Essa crença, por sua vez, reforça a descrença da personagem em relação ao Estado, capaz apenas de lhe apresentar um pseudoatestado da morte de Raimundo. Assim, as buscas de Joana na tentativa de reencontrar o marido adquirem o sentido de uma tentativa de reparar injustiças. Isso porque, na camada superficial do texto, a busca de Joana por Raimundo sugere a persistência da viúva inconformada com a morte do marido, mas, simbolicamente, a personagem incorpora uma insistente busca por verdades que, assim como o corpo de Raimundo, jamais foram reveladas pelos responsáveis pela ditadura militar no Brasil.

Compreende-se, portanto, o par Joana-Raimundo, ambos "trabalhadores comuns", como uma representação de trabalhadores oprimidos por um sistema autoritário evidenciado pelas ações da ditadura. Sob a perspectiva desse Estado autoritário, a articulação de Raimundo junto a um grupo da Ação Popular transforma-o em possível ameaça, já que passa de "trabalhador comum” para "trabalhador organizado". Raimundo, por sua vez, incorpora simbolicamente as perseguições da ditadura a trabalhadores organizados que poderiam representar algum perigo de reação coletiva ao regime. A forma como o assassinato de Raimundo é narrado, de maneira breve e com o personagem totalmente passivo, salienta ainda mais o tom de abuso de poder da disputa desigual de forças entre um trabalhador e o Estado ditatorial.

Sob essa perspectiva, a concepção de justiça representada no conto pelo sistema ditatorial se organiza pela utilização da lei em defesa do próprio regime e contra cidadãos comuns, como Joana e Raimundo. Essa instrumentalização da justiça pelo Estado se materializa no conto, primeiramente, no assassinato de Raimundo pela polícia em função de uma suposta ameaça ao projeto de poder ditatorial e, em seguida, na omissão de informações sobre o óbito e do próprio corpo do trabalhador. Constitui-se, assim, o efeito 
de sentido da impunidade a serviço dos militares envolvidos no crime. Essa impunidade, porém, é colocada em permanente tensão pelas peregrinações de Joana que, ao não deixar morrer a história de Raimundo, mantém visível um cenário que, apesar da aparente normalidade, ainda conserva em segredo crimes como o cometido contra Raimundo, os quais são dados como concluídos apenas por instrumentos legais como o "pseudoatestado" contestado pela viúva que insiste em exigir ver o "corpo" do seu marido e, simbolicamente, fazer ver a verdade sobre o período ditatorial.

Desta forma, a partir de uma convincente elaboração da perspectiva de um narrador-advogado que contesta o autoritarismo e demais abusos cometidos pela ditadura, o conto "Joana" constrói seus sentidos pela oposição entre justiça e injustiça. A protagonista Joana, vinculada ao campo da "justiça", assume para si a missão de revelar por completo a injustiça cometida contra Raimundo. No entanto, o próprio narrador reconhece a dificuldade dessa tarefa, uma vez que a habilidade e o poder dos criminosos em omitir o corpo de Raimundo, sem deixar nenhuma pista, impede que a justiça se cumpra. Nesse sentido, a manutenção das omissões ao final do conto, tanto do corpo de Raimundo quanto, simbolicamente, de muitos crimes cometidos pela ditadura, indica a manutenção de um sistema que, além de proteger os responsáveis pelo cometimento desses crimes, continua a produzir cada vez mais pobreza, já que Joana sempre encontra em suas peregrinações algum "novo" andarilho para perguntar sobre Raimundo. Por outro lado, Joana, ao contestar a verdade parcial apresentada pelo Estado, reveste-se de certo heroísmo, pois, além de colocar a versão "oficial” em xeque e continuar buscando a revelação da verdade por completo, suas insistentes peregrinações, sempre entre os "indigentes", mantêm os segredos da ditadura sob tensão. Assim, da perspectiva do narrador, é como se o amor de Joana emergisse da sua resistência à ditadura e ao tempo que, apesar de "tudo devorarem", não foram capazes de "extinguir" o amor da viúva que a mantém em busca de toda a verdade a respeito do que acontecera com seu marido.

\section{Considerações Finais}


A partir da análise do conto "Joana", em diálogo com outros estudos sobre a obra de Bernardo Kucinski, foi possível notar a maneira como a produção literária do escritor denuncia que os processos legais contra os crimes cometidos pela ditadura, em vez de resultarem no reconhecimento desses abusos e, consequentemente, em cuidados para que novos regimes autoritários não voltassem a se estabelecer no país; acabaram funcionando mais para conferir uma aparência de normalidade aos abusos pela ditadura. Sendo assim, é possível considerar a obra de Kucinski como uma forma de resposta à tentativa do Estado de apagar trajetórias desaparecendo com corpos e silenciando narrativas. A própria atitude do escritor de tomar depoimentos de vítimas desse período como material de elaboração narrativa reforça a percepção sobre a sua intenção de potencializar aquilo que é dito e silenciado nesses depoimentos, uma vez que a forma literária é capaz de tornar mais visível todo o contexto que envolveu os acontecimentos relatados.

Nesse sentido, o conto "Joana", a exemplo de outras produções de Kucinski, inscreve-se no conjunto de obras da história da literatura brasileira que tematizaram uma racionalidade de Estado orientada pela gestão da morte. A obra de Kucinski, entretanto, não reproduz esse modelo de pensamento, pelo contrário, pois além de denunciar a ditadura brasileira como um período marcado pelo anúncio, em tom de ameaça, de um projeto político fortemente orientado por essa lógica de controle da vida e da morte por parte do Estado, ressoa vozes que, a exemplo de Joana, insistem em não deixar silenciarem os apelos de justiça contra os crimes cometidos nesse período.

\section{REFERÊNCIAS}

ANDERSSON, L. M. S. As Cadeias da Humanidade são Feitas de Papel: o testemunho da ditadura civil-militar no romance K. Tese (Doutorado em Literatura Comparada) Programa de Pós-Graduação em Ciência da Literatura da Universidade Federal do Rio de Janeiro (UFRJ), Rio de Janeiro, 2014. Disponível em: $<$ https://sucupira.capes.gov.br/sucupira/public/consultas/coleta/trabalhoConclusao/view TrabalhoConclusao.jsf?popup=true\&id_trabalho=1998826>. Acesso em 29 jul. 2021; 
ARAUJO, C. G. B. DE; FERNANDES, F. F. A Representação da Violência em Você Vai Voltar pra mim e Outros Contos, de Bernardo Kucinski. XV ABRALIC: experiências literárias textualidades contemporâneas. Anais...2016. Disponível em: <https://abralic.org.br/anais/arquivos/2016_1491488386.pdf>. Acesso em 29 jul. 2021;

DINIZ, D. Vida(s), Política \& Processo Civilizatório no Sistema Literário Brasileiro. In: WERKEMA, A. S.; OLIVEIRA, A. L. M. DE; SOARES, M. V. N. (Org.). Figurações do real (literatura brasileira em foco VII). Belo Horizonte: Relicário Edições, 2017. p. 141-176;

KUCINSKI, B. Você Vai Voltar pra Mim e Outros Contos. São Paulo: Cosac Naify, 2014

SANTOS, C. N. DOS; FONSECA, C. L. O Entre-Lugar dos Desaparecidos Políticos em K. Relato de uma Busca e Você Vai Voltar pra mim e Outros Contos, de Bernardo Kucinski. Caderno de Letras. Anais...2018. Disponível em: $<$ https://abralic.org.br/anais-artigos/?id=1482>. Acesso em 29 jul. 2021;

VASCONCELOS, L. H. DA S. Memória, Testemunho, Trauma e Luto em Você Vai Voltar pra mim e Outros Contos, de Bernardo Kucinski. Dissertação (Mestrado em Letras na área de Estudos Literários) - Programa de Pós-Graduação em Letras, da Faculdade de Letras, da Universidade Federal do Amazonas (UFAM), Manaus, 2018. Disponível em: 〈https://tede.ufam.edu.br/handle/tede/6766>. Acesso em 29 jul. 2021. 